\title{
Symptoms based cancer diagnosis-An inconceivable strategy
}

Williams Fernandes Barra ${ }^{1}$, Taíssa Maíra Thomaz Araújo ${ }^{1}$, Danielle Queiroz Calcagno ${ }^{1}$, André Salim Khayat ${ }^{1}$, Sidney Emanuel Batista dos Santos $^{1}$, Ney Pereira Carneiro dos Santos ${ }^{1}$, Carolina Baraúna Assumpção ${ }^{1}$, Aline Maria Pereira Cruz ${ }^{1}$, Geraldo Ishak ${ }^{2}$, Ândrea Kely Campos Ribeiro-dos-Santos ${ }^{1}$, Rommel Mario Rodriguez Burbano ${ }^{1}$, Gregory Joseph Riggins ${ }^{3}$ and Paulo Pimentel de Assumpção ${ }^{*}$

${ }^{1}$ Núcleo de Pesquisas em Oncologia, Belém, Pará, Brazil

${ }^{2}$ Hospital Universitário João de Barros Barreto, Belém, Pará, Brazil

3Johns Hopkins Medicine, Department of Neurosurgery, Johns Hopkins University, Baltimore, Maryland, United States

\begin{abstract}
Worldwide an increasing amount of money is expended to fight cancer. The treatment of advanced cancers corresponds to most expenses and worst results. Early diagnosis is an absolute exception in developing countries. Usually, cancer diagnosis is based on the presence of symptoms. Prevention is the best-case scenario in the fight against cancer because it is less expensive and more effective. Unfortunately, for a large group of lethal cancers, there are no useful prevention strategies. Recent discoveries of many cancer biomarkers and circulating tumor DNAs opened new avenues of cancer screening strategies to improve public health. With these exciting new techniques, cancer markers are being identified at early stages of disease and even prior to cancer onset, sometimes using minimally invasive and high accessible approaches. These new cancer control methods require substantial increase in the budget allocated to research and development of robust and reproducible assays with great power and precision to allow its global utilization. The development of treatment modalities to combat advanced cancers is an uncontested necessity. However, it seems that a paradigm shift is required; society must invest a greater percent of the available cancer research budget to improve prevention and early identification technologies. Waiting for symptoms to diagnose cancer is a death sentence for millions of patients worldwide. Waiting for the problem to become giant before fighting it is similar to a suicide strategy. Therefore, it is imperative that scientific minds, technology and money are channeled to support discoveries in cancer prevention and early diagnosis.
\end{abstract}

\section{Cancer diagnosis and health policies}

The fight against cancer remains a global challenge. Nevertheless, an increasing amount of money is expended every year to fight cancer, worldwide.

The costs of cancer treatments have grown exponentially. This rapid growth has occurred mainly after introduction of molecular-targeted therapies. Precision medicine, which represents the gold standard of cancer care, aims to deliver the right medication at the right dose to the right patient but requires almost unattainable costs. There are many additional expenses besides the drug itself, including molecular investigation to check the target, and the cost of obtaining other genetic information connected to drug response and toxicity [1-3].

The cost of each patient treatment regimen is high because the budget for cancer treatment research is limited, and it takes a long time to develop new drugs and obtain approval for their clinical use $[3,4]$. Most potential drugs in development never reach clinical practice, thus increasing the cost and time required by the pharmaceutic industry to recover its investments [5].

On the other hand, the amount of money lost as a consequence of missed days of work, either by patient or by their relatives due to disease and to treatment related disabilities is very high. Moreover, the price of a life is immeasurable. The number of years of life lost by a patient due to cancer treatment and recovery allows an imprecise estimate of the economic effect of cancer, in addition to the main loss of a human life.

The treatment of advanced cancers corresponds to the majority of expenses and worst results in the general oncology field. Additionally, these are the most common cases in developing countries in which early diagnosis is an absolute exception. This is especially prevalent in poor nations where access to diagnosis and health care is restricted, leading to ineffective cancer care [6].

Usually, cancer diagnosis is based on the presence of symptoms that suggest the possibility of cancer. For a cancer to produce the classical symptoms or signs of cancer such as weight loss, anemia, palpable nodules or mass, digestive obstruction and many others, it will always be a consequence of an advanced cancer, and mostly represent incurable disease [7-9].

With the exceptions of colon, cervical, breast, penile, anal, and hepatitis B related liver cancers, there are no effective public health policies to prevent cancer occurrence or to allow early diagnosis, leading to a real perspective of cure [10-14].

It is well-understood that some cancers are preventable if exposures

Correspondence to: Paulo Pimentel de Assumpção, Rua dos Mundurucus, 4487, Guamá, Belém-PA, CEP 66073-000, Brazil, Tel: 5591984171112; E-mail: assumpcaopp@gmail.com

Key words: cancer diagnosis, cancer treatment costs, cancer prevention, cancer budget, health policies

Received: December 22, 2016; Accepted: January 17, 2017; Published: January 20,2017 
to risk factors are avoided. However, public health interventions usually fail to generate the behavioral modifications that could consequently decrease cancer incidence. Education seems to contribute to the success of public health interventions; nevertheless, even developed countries fail to combat preventable cancers [15].

Prevention is the best-case scenario in the fight against cancer because it is less expensive and more effective for cancer control than current treatment modalities. Unfortunately, for a large group of lethal cancers, there are no useful prevention strategies.

For these cancer types, the current preventative research agenda is to discover molecular markers of risk that will allow surveillance and could lead to future interventions [16-18].

In this field, creative strategies have been attempted, including the following screening modalities: fecal DNA analyses for digestive cancers, urinary and sputum studies and blood tests [19-24].

Recent discoveries of many cancer biomarkers and circulating tumor DNAs open new avenues of cancer screening strategies to improve public health. With these exciting new techniques, cancer markers are being identified at early stages of disease and even prior to cancer onset, sometimes using minimally invasive and high accessible approaches. In the near future, interfering with epigenetic features of cancer cells and editing DNA may provide effective methods to disrupt the carcinogenic process and re-establish healthy cellular status.

These new cancer control methods require substantial increase in the budget allocated to research and development of robust and reproducible assays with great power and precision in order to allow its global utilization.

The development of treatment modalities to combat advanced cancers is an uncontested necessity. However, it seems that a paradigm shift is required; society must invest a greater percent of the available cancer research budget to improve prevention and early identification technologies.

This paradigm shift is inevitable because the current model is unsustainable. The number of cancer cases, as well as the duration of treatment for each case, are increasing, and the prices of the newly approved drugs are elevating. Thus, the long-term costs are unsupportable.

Reductions in cancer incidence and incremental improvements in early diagnosis as a consequence of shift paradigm will allow the continuation of current researches. It should also promote additional investments to develop new drugs against advanced cancers because positive results will reach a financial equilibrium in cancer management due to reduced incidence.

The majority of cancer discoveries that reach clinical practice are related to new drugs that modestly increase survival for patients with advanced cancer. This trend is the consequence of massive investments in these products by the pharmaceutical industry and public agencies. Unfortunately, these improvements in cancer care come with extremely high costs that are insupportable by the majority of nations. The global cancer outlook could be likened to a roaring fire caused by a gas leak. The firefighters are treating it with liters of water, rather than fixing the leak. It is necessary to douse the flames, but if the leak persists, there will never be enough water.

In the era of molecular targeted therapies, it is inconceivable that discovery and diagnosis of cancer is achieved by identifying symptoms.
Technologies being used to discover molecular targets and develop "smart therapies" should also be used to prevent cancer or, at least, discover the disease earlier.

Additionally, it is well accepted that after the occurrence of the earliest alteration (a driver mutation), it takes approximately 20 years to generate a clinically identifiable tumor. In most patients, more years of life are spent harboring an undetected cancer driver mutation than those that elapse from the diagnosis to terminal outcome [25]. This provides an opportunity for scientists to change the outcome for each patient. It may be possible to discover cancer molecular signatures many years before the clinical signs or symptoms appear.

Most of the initial driver mutations and their pathways are already known [25]. Improving the capability to identify these driver mutations in asymptomatic people, especially with minimally invasive approaches, would allow the "at risk" individuals to utilize new strategies for early diagnosis or molecular treatment. For example, molecular imaging technology, which is making dramatic strides in resolution, could be used to discover cells with the driver mutation at a growing tumor site. Upon discovery, these mutant cells could be properly treated at a more easily controllable stage.

A first initiative to change the current state of cancer research is in the hands of the government. Public dollars can be used to motivate scientists to investigate measures that allow earlier diagnosis and identify people at risk based on molecular markers. Reaching these goals depends on directing the research funding budgets to support prevention. The pharmaceutical industry focus on cancer treatment will not be modified a priori because cancer treatment drugs make money and save lives. However, the focus of the government is not only to save lives but also to save money. Both contributions are necessary and mutually beneficial.

A change in cancer research trends is essential. Waiting for symptoms to diagnose cancer is a death sentence for millions of patients worldwide. Waiting for the problem to become giant before fighting it is similar to a suicide strategy. Therefore, it is imperative that scientific minds, technology and money are channeled to support discoveries in cancer prevention and early diagnosis.

\section{Acknowledgment}

We acknowledge Universidade Federal do Pará (PROPESP and Fadesp) for technical support, Conselho Nacional de Desenvolvimento Científico e Tecnológico (CNPq) and Coordenação de Aperfeiçoamento de Pessoal do Nível Superior (CAPES) for financial and fellowship support.

\section{Conflicts of interest}

The authors certify that they have no affiliations with or involvement in any organization or entity with any financial interest (such as honoraria; educational grants; participation in speakers' bureaus; membership, employment, consultancies, stock ownership, or other equity interest; and expert testimony or patent-licensing arrangements), or non-financial interest (such as personal or professional relationships, affiliations, knowledge or beliefs) in the subject matter or materials discussed in this manuscript.

\section{References}

1. Baas P, van Meerbeeck J (2016) Money rules the world. Lung Cancer 91: 77-78.

2. Saltz LB (2015) Can money really be no object when cancer care is the subject? J Clin Oncol 33: 1093-1094. [Crossref] 
3. Dilla T, Lizan L, Paz S, Garrido P, Avendaño C, Cruz-Hernández JJ, et al. (2015) Do new cancer drugs offer good value for money? The perspectives of oncologists, health care policy makers, patients, and the general population. Patient Prefer Adherence 10: 1-7. [Crossref]

4. Siddiqui M, Rajkumar SV (2012) The high cost of cancer drugs and what we can do about it. Mayo Clin Proc 87: 935-943. [Crossref]

5. Gupta UC, Bhatia S, Garg A, Sharma A, Choudhary V (2011) Phase 0 clinical trials in oncology new drug development. Perspect Clin Res 2: 13-22. [Crossref]

6. Cazap E, Magrath I, Kingham TP, Elzawawy A (2016) Structural Barriers to Diagnosis and Treatment of Cancer in Low- and Middle-Income Countries: The Urgent Need for Scaling Up. J Clin Oncol 34: 14-19. [Crossref]

7. Sellam F, Harir N, Khaled MB, Mrabent NM, Salah R, et al. (2015) Delayed diagnosis of pancreatic cancer reported as more common in a population of North African young adults. $J$ Gastrointest Oncol 6: 505-510.

8. Pasechnikov V, Chukov S, Fedorov E, Kikuste I, Leja M (2014) Gastric cancer: prevention, screening and early diagnosis. World J Gastroenterol 20: 13842-13862. [Crossref]

9. Hamilton W (2010) Cancer diagnosis in primary care. Br J Gen Pract 60: 121-128. [Crossref]

10. Wang CH, Wey KC, Mo LR, Chang KK, Lin RC, et al. (2015) Current trends and recent advances in diagnosis, therapy, and prevention of hepatocellular carcinoma. Asian Pac $J$ Cancer Prev 16: 3595-604.

11. Tota JE, Ramana-Kumar AV, El-Khatib Z, Franco EL (2014) The road ahead for cervical cancer prevention and control. Curr Oncol 21: e255-264. [Crossref]

12. Shabbir M, Barod R, Hegarty PK, Minhas S (2013) Primary prevention and vaccination for penile cancer. Ther Adv Urol 5: 161-169. [Crossref]

13. Massat NJ, Moss SM, Halloran SP, Duffy SW (2013) Screening and primary prevention of colorectal cancer: a review of sex-specific and site-specific differences. $J \mathrm{Med}$ Screen 20: 125-148. [Crossref]
14. Swedish KA, Factor SH, Goldstone SE (2012) Prevention of recurrent high-grade anal neoplasia with quadrivalent human papillomavirus vaccination of men who have sex with men: a nonconcurrent cohort study. Clin Infect Dis 54: 891-898.

15. Doran CM, Ling R, Byrnes J, Crane M, Shakeshaft AP, et al. (2016) Benefit Cost Analysis of Three Skin Cancer Public Education Mass-Media Campaigns Implemented in New South Wales, Australia. PLoS One 11: e0147665.

16. Schmitz-Dräger BJ, Droller M, Lokeshwar VB, Lotan Y, Hudson MA, et al. (2015) Molecular markers for bladder cancer screening, early diagnosis, and surveillance: the WHO/ICUD consensus. Urol Int 94: 1-24. [Crossref]

17. Dickinson BT, Kisiel J, Ahlquist DA, Grady WM (2015) Molecular markers for colorectal cancer screening. Gut 64: 1485-1494.

18. Baron JA (2012) Screening for cancer with molecular markers: progress comes with potential problems. Nat Rev Cancer 12: 368-371. [Crossref]

19. Dhaliwal A, Vlachostergios PJ, Oikonomou KG, Moshenyat Y (2015) Fecal DNA testing for colorectal cancer screening: Molecular targets and perspectives. World $J$ Gastrointest Oncol 7: 178-183. [Crossref]

20. Huddy JR, Ni MZ, Markar SR, Hanna GB (2015) Point-of-care testing in the diagnosis of gastrointestinal cancers: current technology and future directions. World $J$ Gastroenterol 21: 4111-4120.

21. Wei JT (2015) Urinary biomarkers for prostate cancer. Curr Opin Urol 25: 77-82. [Crossref]

22. Schwarzenbach H, Pantel K (2015) Circulating DNA as biomarker in breast cancer. Breast Cancer Res 17: 136. [Crossref]

23. Heichman KA (2014) Blood-based testing for colorectal cancer screening. Mol Diagn Ther 18: 127-135. [Crossref]

24. Loeb S, Catalona WJ (2014) The Prostate Health Index: a new test for the detection of prostate cancer. Ther Adv Urol 6: 74-77. [Crossref]

25. Vogelstein B, Papadopoulos N, Velculescu VE, Zhou S, Diaz LA Jr, et al. (2013) Cancer genome landscapes. Science 339: 1546-1558. [Crossref]

Copyright: $@ 2017$ Barra WF. This is an open-access article distributed under the terms of the Creative Commons Attribution License, which permits unrestricted use, distribution, and reproduction in any medium, provided the original author and source are credited. 